\title{
Notes
}

\section{MORPHOLOGY OF THERMOTROPIC POLYESTERS WITH AZOXYBENZENE MOIETY EXAMINED BY OPTICAL MICROSCOPY}

\author{
Yoji Maeda \\ Research Institute for Polymers and Textiles, 1-1-4 Higashi, Tsukuba, Ibaraki, 305 Japan
}

\begin{abstract}
Morphological observation of the texture of thermotropic polyester, poly(4,4'-dioxy-2,2'dimethylazoxybenzene alkanedioyl) has been performed by using a polarized microscope equiped with a hot stage. The observation showed that the oily streak texture of the nematic phase changes dramatically in the nematic-isotropic biphasic region.
\end{abstract}

Thermotropic liquid crystalline polymers have been intensively studied from both theoretical and practical points of view. Blumstein et al. $(1-4)$ described the synthesis and thermal properties of main-chain nemat ic polyesters of poly(4,4'-dioxy-2,2'-dimethylazoxy. benzene alkanedioyl). The polymer consists of a regu. lar sequence of rigid azoxybenzene mesogenic core (mesogen 9) and flexible alkanedioate "spacer" group as shown below.

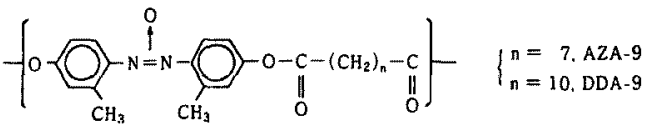

The polyesters show a remarkable odd-even effect in both transition temperature and entropy of nematic (N) - isotropic (I) transition [2]. Such polyesters are characterized by random coil conformation and high flexibility in the melt well above the isotropisation temperature. On cooling from the melt, the polymer can transit through a nematic mesophase before crys. tallizing or vitrification. In this paper, we present preliminary results on the temperature dependence of morphological texture of the thermotropic polyesters by polarizing microscopy.

The synthesis and properties of the thermotropic polyesters were described elsewhere (2-4]. The number-average molecular weights $\vec{M}_{\mathfrak{n}}$ of DDA-9 and AZA-9 were 20,000 and 36,000 , respectively. The phase transition of DDA-9 occurs as K120N164I $[5,6]$, where $\mathrm{K}$ denotes the crystal, $\mathrm{N}$ the nematic and $I$ the isotropic liquid phase. On the other hand, the transition of AZA-9 occurs as G17N $148 \mathrm{I}[5,6]$. where $G$ indicates the nematic glass. The compounds were highly stable within the temperature ranges. Polarizing microscopic observation was carried out by using a Leitz Orthoplan microscope equipped with a Mettler FP84 hot stage. The textures of the AZA-9 and DDA-9 samples were observed at a scanning rate of $1{ }^{\circ} \mathrm{C} / \mathrm{min}$ under nitrogen atmosphere.

Fig. 1 shows the polarized microphotographs of the morphology for the DDA-9 sample in the heating pro. cess. This illustrates clearly the characteristic textures during the $\mathrm{N}-\mathrm{I}$ phase transition of the thermotropic polyester. The oily streak texture was observed in the mesomorphic region of about 130 $150^{\circ} \mathrm{C}$. It changed gradually but dramatically to no texture of the isotropic liquid phase as the temperature increased. First, the oily streak texture was cov. ered with small microspheres on the whole area at about $150-155^{\circ} \mathrm{C}$. Then the microspheres increased with temperature and then the texture changed to the so-called "percolation networks" pattern in the nematic-isotropic biphasic region of $156-163^{\circ} \mathrm{C}$. The percolation networks [7] consisted of the nematic phase of bright networks among the isotropic liquid phase of dark sea area. The area of the dark region in creased with temperature, while the nematic networks were broken into many curved islands. Then, these islands shrank gradually into small spots. The bright spots became smaller, and they disappeared finally into the isotropic liquid state at $164^{\circ} \mathrm{C}$ and above. Fig. 2 shows the microphotographs of the DDA-9 sample on cooling from the isotropic liquid phase. The oily streak texture of the nematic phase was cov- 

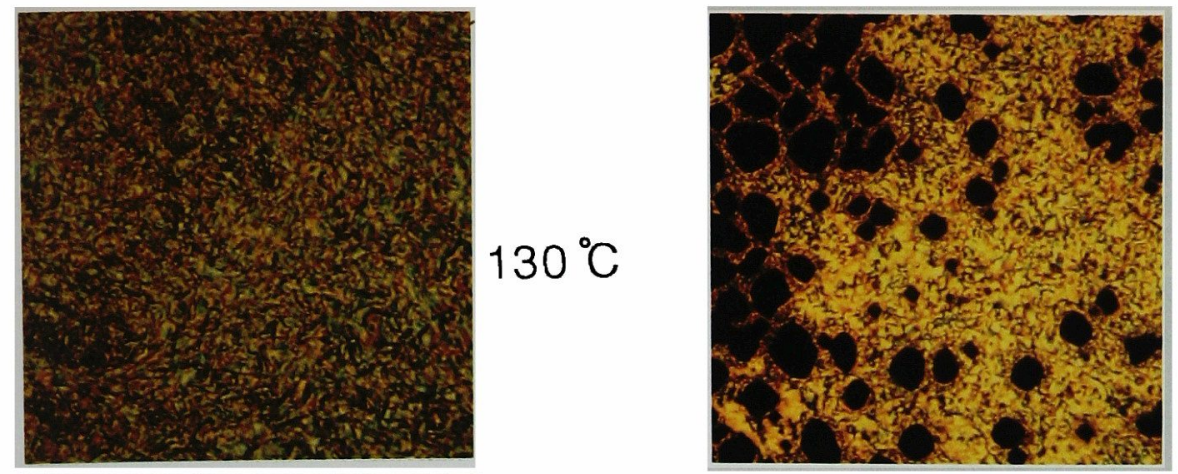

$158^{\circ} \mathrm{C}$

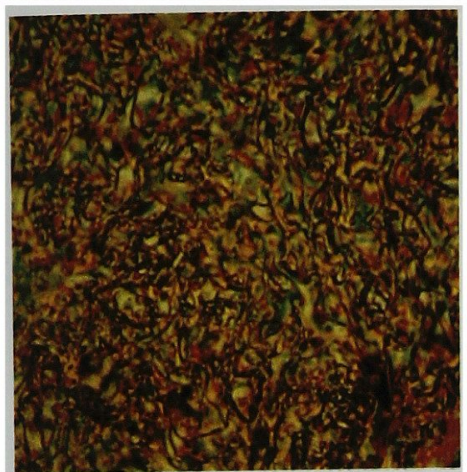

$145^{\circ} \mathrm{C}$

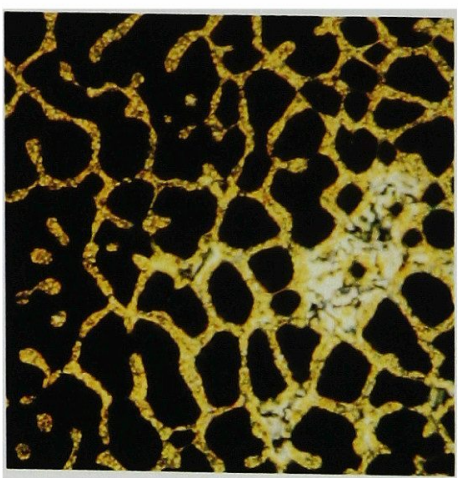

$159^{\circ} \mathrm{C}$
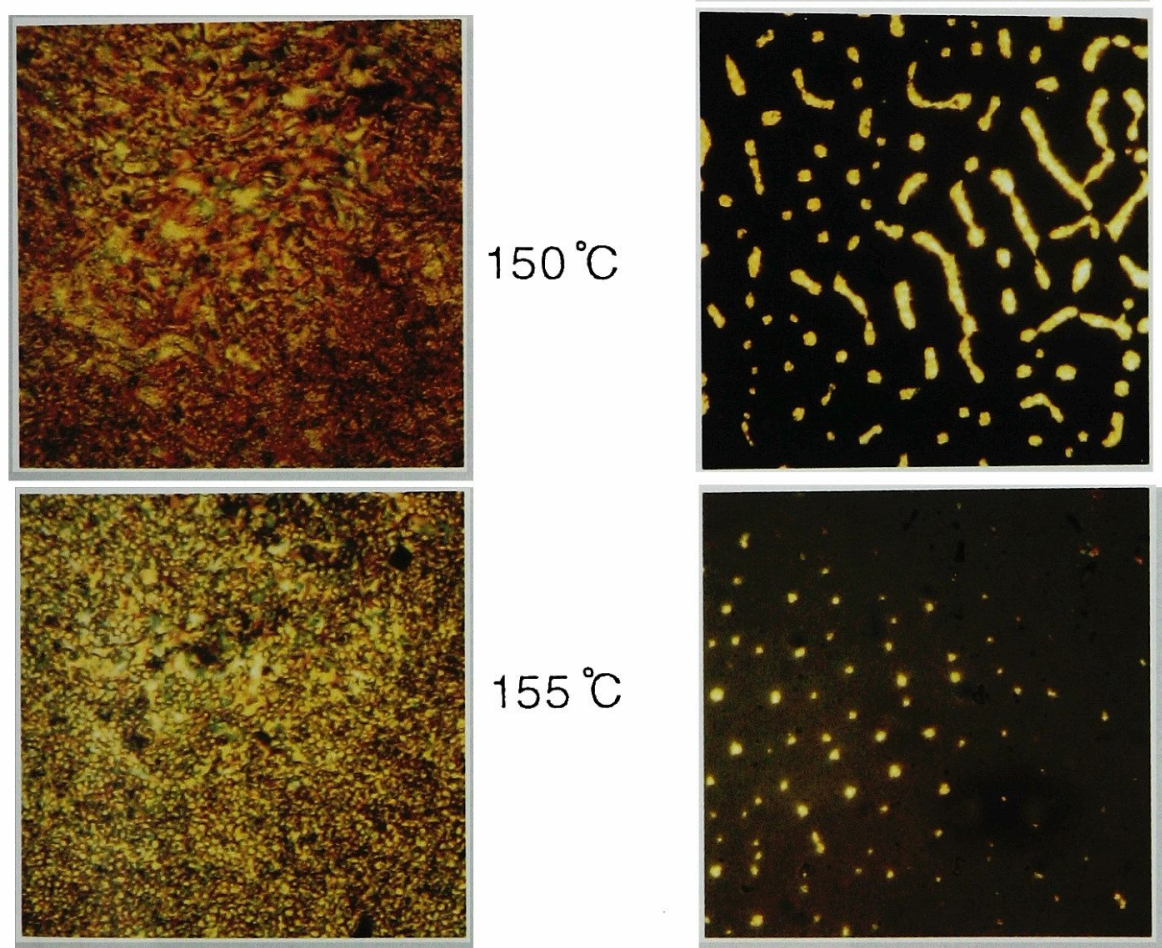

$161^{\circ} \mathrm{C}$

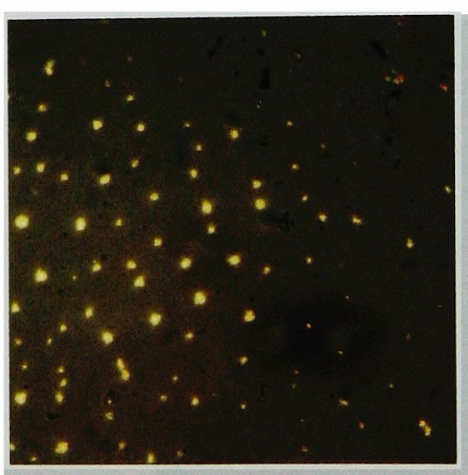

$162{ }^{\circ} \mathrm{C}$

Fig. 1. Polarized photomicrographs of the textures of the DDA-9 polyester at indicated temperatures on heating. Magnification: $\times 320$. Bar indicates the length of $10 \mu \mathrm{m}$. 

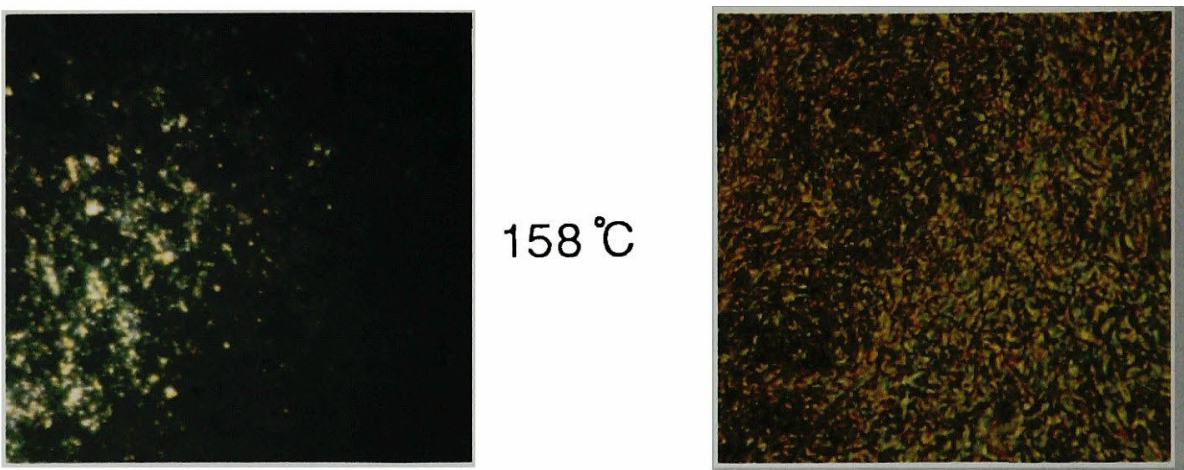

$120^{\circ} \mathrm{C}$
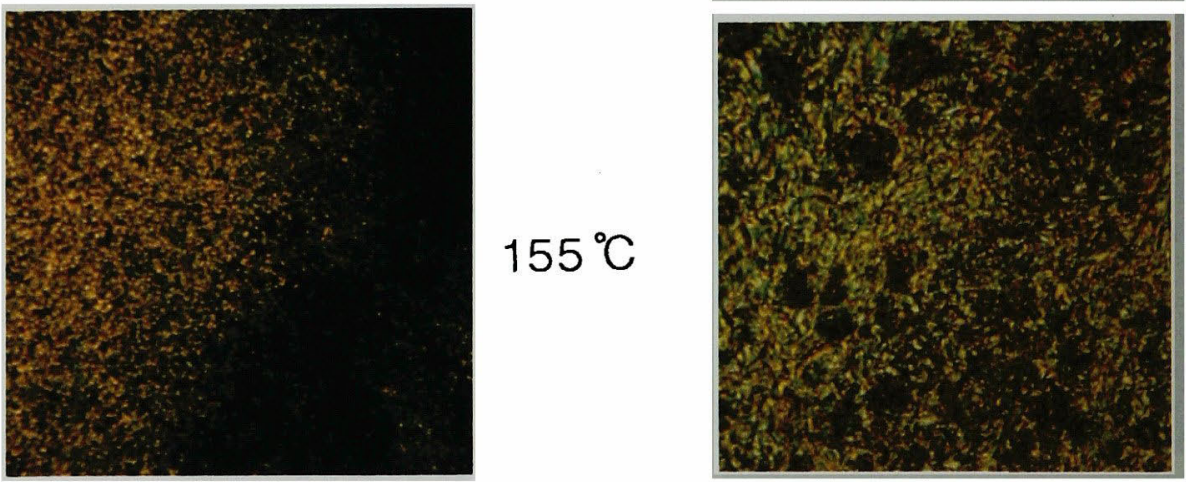

$105^{\circ} \mathrm{C}$

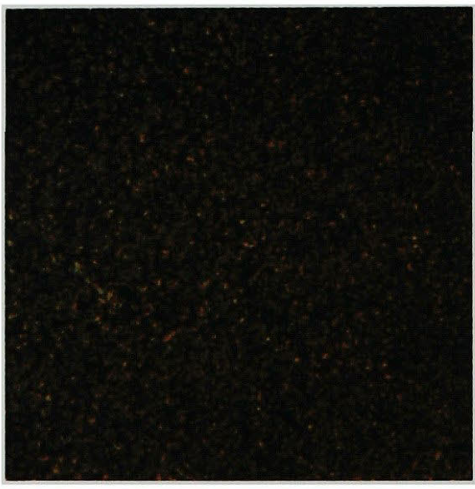

$151^{\circ} \mathrm{C}$
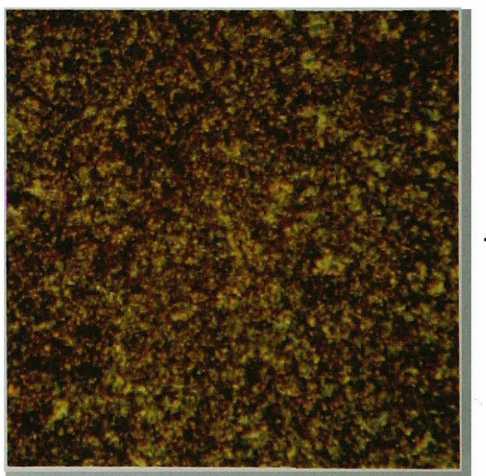

$100^{\circ} \mathrm{C}$

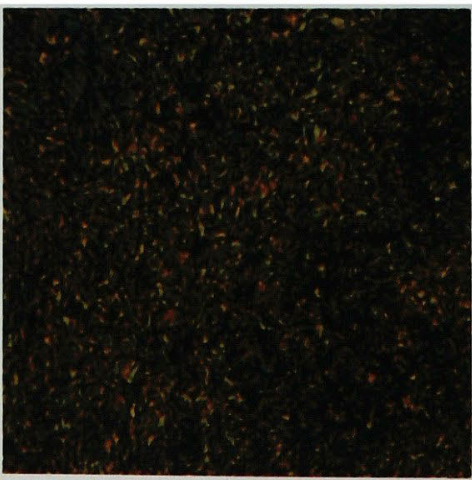

$135^{\circ} \mathrm{C}$

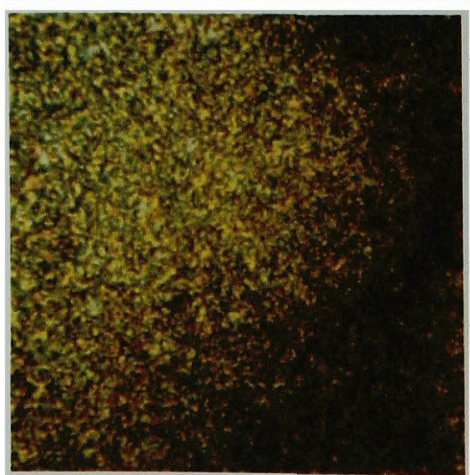

$30^{\circ} \mathrm{C}$

Fig. 2. Polarized photomicrographs of the textures of the DDA-9 polyester on cooling from the isotropic liquid phase. Magnification: $\times 320$. 

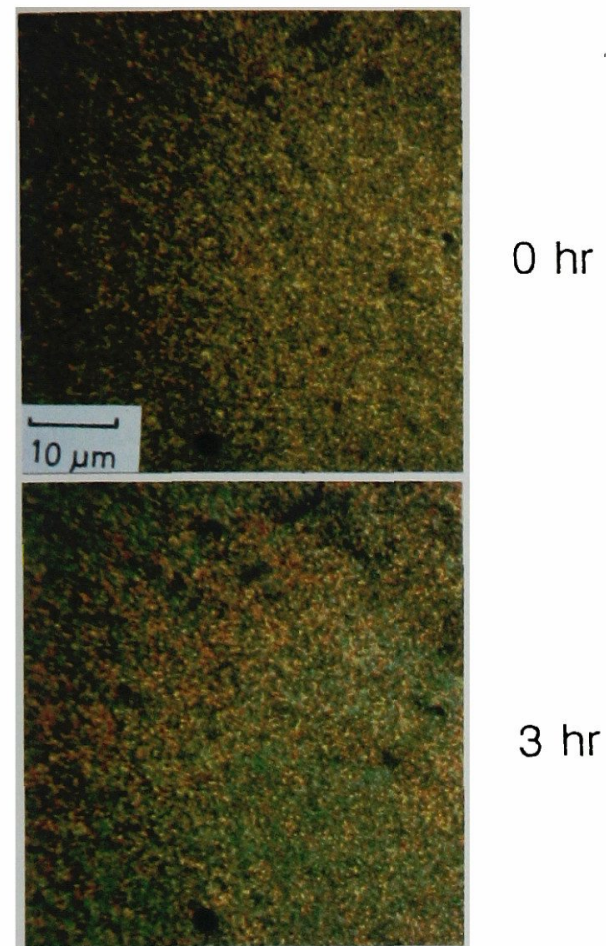

$3 \mathrm{hr}$

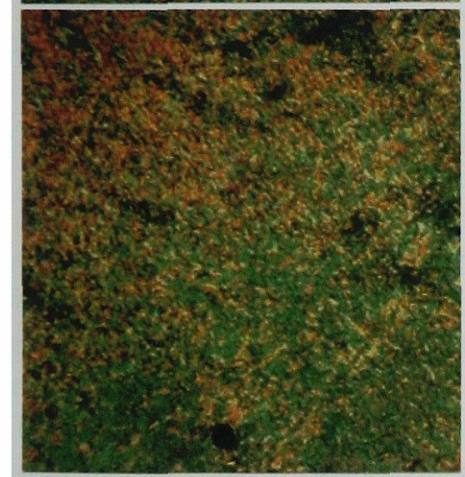

$16 \mathrm{hr}$

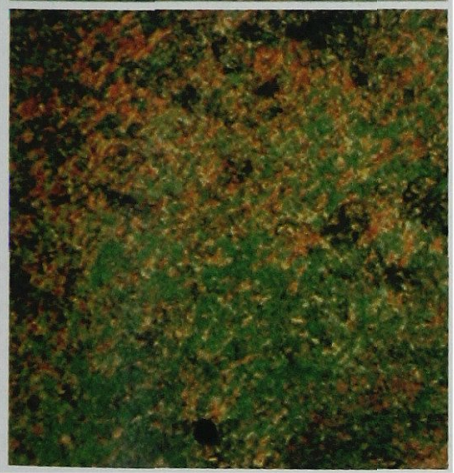

Fig. 3. Polarized photomicrographs of the textures of the AZA-9 polyester annealed at $70{ }^{\circ} \mathrm{C}$ for the indicated periods of time. Magnification: $\times 320$. ered with the dense texture of crystals at 105-100 ${ }^{\circ} \mathrm{C}$, indicating visually the transition from the nematic phase to the crystals. Thus the transition points can be determined morphologically on cooling process. The changes in texture of AZA-9 on the N-I transition showed almost the same patterns as those in the DDA-9 sample. On the other hand, the nematic state of AZA-9 was easily vitrified to the glassy state without crystallizing. The nematic texture was frozen at room temperature, corresponding to the thermal behavior on vitrification of the nematic phase $[5,6]$. It is also known that the AZA-9 nematic glass can be transformed to the crystalline state by aging at room temperature for long time or by annealing at higher temperatures. Fig. 3 shows the change in texture of the nematic glass of AZA- 9 by annealing at $70{ }^{\circ} \mathrm{C}$ for different periods of time. It is evident that the glassy texture is transformed to a typical crystalline texture such as those of DDA-9 with increasing annealing periods.

The texture of DDA-9 and AZA-9 samples during the nematic-isotropic transition suggest the phase separation of the nematic phase from the isotropic liquid domains [7]. d'Allest et al. [8] reported on the nematic-isotropic biphasic behavior of the DDA-9 polyester. The present results correspond to their results of an orientational ordering followed by macroscopic demixing of the nemanic and isotropic domains.

\section{ACKNOWLEDGEMENTS}

The author is grateful to Prof. A. Blumstein of Lowell University for kindly supplying the thermotropic polyesters and for helpful discussion.

\section{REFERENCES}

1. A. Blumstein and O. Thomas, Macromolecules, 15, 1264 (1982)

2. A. Blumstein and S. Vilasagar, Mol. Cryst. Liq. Crist. (Letters), 72, 1 (1981)

3. A. Blumstein, S. Vilasagar, S. Ponrathnam, S. B. Clough, R. B. Blumstein, and G. Maret, J. Polym. Sci., Polym. Phys. Ed., 20, 877 (1982)

4. R. B. Blumstein, E. M. Stickles, M. M. Gauthier, A. Blumstein, and F. Volino, Macromolecules, 17, 177 (1984)

5. Y. Maeda, Rep. Prog. Polym. Phys. Japan, 31, 
211 (1988): 31, 217 (1988)

6. Y. Maeda. Thermochimica Acta, 163, 211 (1990)

7. T. Shiwaku, A. Nakai, H. Hasegawa, S. Suehiro, and T. Hashimoto, Polymer preprint, Japan, $\mathbf{3 6}$,
970 (1987)

8. J. F. d'Allest, P. Sixou, A. Blumstein, and R. Blumstein, ACS Symposium, Aug., 1987 